\title{
miR-98 targets ITGB3 to inhibit proliferation, migration, and invasion of non-small-cell lung
} \section{cancer}

This article was published in the following Dove Press journal:

OncoTargets and Therapy

22 September 2015

Number of times this article has been viewed

\section{$\operatorname{Ran} \mathrm{Ni}^{1}$ \\ Yongjie Huang ${ }^{2}$ \\ Jing Wang'}

'Department of Respiration Medicine, ${ }^{2}$ Department of Geriatric Respiration and Sleep, The First Affiliated Hospital of Zhengzhou University, Zhengzhou, Henan, People's Republic of China
Correspondence: Jing Wang Department of Respiration Medicine, The First Affiliated Hospital of Zhengzhou University, East Jianshe Road I, Zhengzhou 450052, People's Republic of China

Tel +86 037I 66862182

Email wangjing66well@।63.com
Background: Accumulating evidence has emphasized causative links between aberrant microRNA (miR) expression patterns and cancer development. Abnormally expressed miRNA-98 (miR-98) was found in certain types of human cancers. The biological roles of miR-98 in lung cancer, however, remain largely undefined.

Methods: We evaluated the expression of miR-98 in normal lung tissues, lung cancer tissues, normal human bronchial epithelial cells, and lung cancer cells using quantitative real-time polymerase chain reaction. Effect of miR-98 on proliferation of lung cancer cells was investigated using MTT assay and colony formation assay. Transwell assay was used to assess the effects of miR-98 on migration and invasion of lung cancer cells. Whether miR-98 targets the $3^{\prime}$-untranslated region (3'-UTR) of integrin $\beta 3$ (ITGB3) coding gene ITGB3 mRNA was ascertained using luciferase reporter assay. Finally, we transplanted miR-98 expressing A549 cells into nude mice to observe the effect of miR-98 on tumor growth in vivo.

Results: We confirmed that miR-98 was frequently low expressed in lung cancer tissues and human lung cancer cells. Reintroduction of miR-98 into lung cancer cells inhibited cell proliferation, migration, and invasion in vitro and suppressed tumor formation in a nude mouse model. Furthermore, we identified that miR-98 exerted inhibitory roles by directly binding to 3 '-UTR of $I T G B 3 \mathrm{mRNA}$, thus negatively regulated the expression of ITGB3. Interestingly, upon restoring the expression of ITGB3, the effect of miR-98 on cell proliferation was partially reversed.

Conclusion: Our findings suggest that miR-98 prevents proliferation, migration, and invasion of lung cancer cells by directly binding to the 3'-UTR of ITGB3 mRNA and could be a promising treatment option in anticancer therapy.

Keywords: miR-98, proliferation, migration, invasion, integrin $\beta 3$ (ITGB3)

\section{Introduction}

Lung cancer continues to be the most common and is the cancer causing the highest mortality rate worldwide during the past several decades. The incidence rate is still increasing, especially in the People's Republic of China. ${ }^{1-3}$ According to previous statistics, the incidence and mortality number of lung cancer, respectively, reached 1.24 million and 1.10 million in global in 2012, ${ }^{4}$ and in the People's Republic of China, the corresponding incidence and mortality number were over 0.61 million and 0.49 million in $2010 .{ }^{5}$ There are increasing evidences that multiple factors, including genetic factors, environmental factors, and their interactions, are involved in the occurrence and development of lung cancer, such as smoking, chronic pulmonary disease, ${ }^{6}$ air pollution, ${ }^{7}$ and gene polymorphisms. ${ }^{8,9}$ However, the potential mechanism of lung cancer pathogenesis is still poorly understood. 
MicroRNAs (miRNAs or miRs) represent a class of single-stranded noncoding RNAs with the length of 18-25 nucleotides. ${ }^{10,11}$ As a kind of posttranscriptional regulators of gene expression, miRs are involved in the regulating of many central biological processes, such as cell development, ${ }^{12}$ cell proliferation, ${ }^{13}$ cell differentiation, ${ }^{14}$ cell apoptosis, ${ }^{15}$ fat metabolism ${ }^{16}$ and so on. As reported, thrombogenicity and other tissue factor-mediated processes play an important role in several types of cancer, such as lung cancer. ${ }^{17,18}$ Recently, there had been more and more studies that showed that miRs may play a very important role in cancer treatment, especially in lung cancer treatment. ${ }^{19,20}$ For examples, $\mathrm{miR}-30 \mathrm{~b} / \mathrm{c}$ inhibits non-small-cell lung cancer (NSCLC) cell proliferation, ${ }^{21}$ miR-34a inhibits growth of NSCLC and the CD44hi stem-like NSCLC cells, ${ }^{22}$ and miR-217 functions as a tumor suppressor and correlates with cell resistance to cisplatin in lung cancer. ${ }^{23}$ As a very vital functional miR, miRNA-98 (miR-98) can regulate tumor metastasis in human esophageal squamous cell carcinoma, ${ }^{24}$ restrain human ovarian cancer stem cell proliferation, ${ }^{25}$ inhibit prostate cancer growth ${ }^{26}$ and so on. However, the mechanism of miR-98 on lung cancer pathogenesis is still poorly understood.

Integrins represent a class of transmembrane receptors that play vital roles in signal transduction, especially in the pathogenesis of human cancer. ${ }^{27}$ Integrin $\beta 3$ (ITGB3), which is a integrin beta-chain subunit coded by a serotonin-related gene on chromosome 17, was reported to be associated with the risk of human cancers, such as colorectal cancer. ${ }^{27,28}$ The ITGB3 family includes $\alpha$ IIb $\beta 3$ and $\alpha v \beta 3$. $\alpha$ IIb $\beta 3$ mainly expresses on the surface of platelets and megakaryocytes, while $\alpha v \beta 3$ mainly expresses on the surface of endothelial cells, smooth muscle cells, monocytes, and platelets. ${ }^{18,29,30}$ It is reported that ITGB3 is involved in the pathogenesis of many cancers, especially in lung cancer..$^{27,31}$

In this work, the effects of miR-98 on lung cancer were studied. We found that overexpression of miR-98 could inhibit the proliferation, migration, and invasion of lung cancer cells. By further investigations, we found that these effects may result from direct binding of miR-98 on the $3^{\prime}$-untranslated region (3'-UTR) of ITGB3.

\section{Materials and methods}

\section{Clinical tissues and cell culture}

In all, 26 lung cancer tissue specimens and 26 adjacent noncancerous lung tissue specimens were obtained from patients with NSCLC in our hospital. A summary of patient characteristics and some pathological features is listed in Table 1.

Normal human bronchial epithelial cells and lung cancer cells H1650, HCC827, NCL-H358, SKMES-1, PC9,
Table I Clinic-pathological characteristics

\begin{tabular}{ll}
\hline Characteristics & Patients $(\mathbf{n}=\mathbf{2 6})$ \\
\hline Median age (range) & $62(45-77)$ years \\
Sex (M/F) & $16 / 10$ \\
Smokers & 15 \\
Stage & \\
I & 8 \\
II & 18 \\
Histotype & \\
$\quad$ Adenocarcinoma & 22 \\
$\quad$ Large cell carcinoma & 4 \\
Metastatic sites & \\
I & 11 \\
$\geq 2$ & 7 \\
\hline
\end{tabular}

Abbreviations: $M$, male; $F$, female.

and A549 were cultured in RPMI-1640 medium (Thermo Fisher Scientific, Waltham, MA, USA), supplemented with $10 \%$ fetal bovine serum (FBS), $100 \mathrm{IU} / \mathrm{mL}$ penicillin, and $100 \mathrm{IU} / \mathrm{mL}$ streptomycin (Sigma-Aldrich Co., St Louis, MO, USA) at $37^{\circ} \mathrm{C}$ in a humidified atmosphere of $5 \% \mathrm{CO}_{2}$. The cells were passaged every $2-3$ days to maintain exponential growth. This study was approved by the ethics committee of the First Affiliated Hospital of Zhengzhou University, and the informed consent form was obtained by each subject.

\section{Quantitative real-time polymerase chain reaction}

Total RNA including the miR fraction was collected using RNeasy Plus Mini Kit (Qiagen NV, Venlo, the Netherlands) according to the manufacturer's protocol. The miR-98 expression was determined by TaqMan MicroRNA Assay (Thermo Fisher Scientific), and expression levels of miR-98 between lung tissues, normal tissues, lung cancer cells, and human bronchial epithelial cells were compared.

\section{Western blotting analysis}

Western blotting analysis was performed to detect the expression of ITGB3. Briefly, protein extracts were subjected to $12 \%$ SDS-PAGE and then transferred onto a polyvinylidene fluoride membrane (Bio-Rad Laboratories Inc., Hercules, CA, USA), probed with antibodies against human integrin $\beta 3$ (Abcam, Cambridge, UK). Peroxidase-conjugated secondary antibodies were used to detect primary antibodies according to the manufacturer's recommendations and then visualized on chemiluminescence-imaging device ImageQuant RT ECL (GE Healthcare Bio-Sciences Corp., Piscataway, NJ, USA).

\section{MTT assay}

Effect of miR-98 on proliferation of lung cancer cells was studied by measuring the relative absorbance of PC9 and A549 cells by using MTT Cell Viability Assay Kit (R\&D 
Systems, Inc., Minneapolis, MN, USA), strictly following the manufacturer's instructions. Briefly, PC9 and A549 cells were seed in a 96-well tissue culture plate $\left(1 \times 10^{4}\right.$ cells $\left./ \mathrm{mL}\right)$ and incubated for 4 days. For MTT assay, $15 \mu \mathrm{L}$ of MTT ( $5 \mathrm{mg}$ / $\mathrm{mL}$; Promega Corporation, Fitchburg, WI, USA) was added to each well and incubated at $37^{\circ} \mathrm{C}$ for 4 hours. At the end of the incubation period, the untransformed MTT was removed and $100 \mu \mathrm{L}$ of dimethyl sulfoxide was added to each well to lyse the cells. The absorbance value of each well was read at a wavelength of $490 \mathrm{~nm}$ using a SpectraMax Microplate Spectrophotometer (Molecular Devices Corporation, Sunnyvale, CA, USA). All these assays were performed in triplicate.

\section{Colony formation assay}

Effect of miR-98 on the overall survival of cells was assessed by measuring the colony number of the PC9 and A549 cells following colony formation assay. Briefly, cells in the miR-98 control group and the miR-98 mimics group were fixed with methanol for 8-12 minutes and stained with crystal violet for $10-15$ minutes.

\section{Cell migration assay}

Effect of miR-98 on migration of lung cancer cells was measured by transwell assay. Transwell membrane (Corning Incorporated, Corning, NY, USA) was used. PC9 and A549 cells were trypsinized, washed, and kept suspended in medium without FBS. To the lower compartment, RPMI-1640 with $10 \%$ FBS was added as the chemotactic factor. A total of $2 \times 10^{4}$ cells in serumfree medium were added to the upper compartment of the chamber. The chamber was placed into a humidified incubator and incubated for 12 hours. Assay was stopped, and the nonmigrated cells were carefully removed with a cotton swab. Migrated cells were fixed and stained with $20 \%$ Giemsa solution. Evaluation of migrated cells at the lower membrane side was performed using the microscope in three different fields per filter.

\section{Cell invasion assay}

The invasive ability of PC9 and A549 cells was examined by membrane transwell culture system. Briefly, transwell membrane coated with Matrigel $(2.5 \mathrm{mg} / \mathrm{mL}$; BD Biosciences Discovery Labware, Woburn, MA, USA) was used. The invasion chambers were rehydrated with serum-free RPMI-1640 for 2 hours at $37^{\circ} \mathrm{C}$. A total of $0.75 \mathrm{~mL}$ of RPMI- 1640 medium with $100 \mathrm{~mL} / \mathrm{L}$ FBS was added to the bottom chambers of the transwell as a chemoattractant. Then, $1.5 \times 10^{5}$ suspended cells in serum-free Dulbecco's Modified Eagle's Medium (Thermo Fisher Scientific) were added to the top chambers of the transwell. After incubation for 12 hours at $37^{\circ} \mathrm{C}$, the invaded cells on the lower surface of the membrane were fixed with methanol, stained with $20 \%$ Giemsa solution, and counted using a light microscope at a magnification of $200 \times$ in three randomly selected fields. The experiments were performed thrice in triplicate.

\section{Transfections}

PC9, SKMES-1, and A549 cells $\left(2 \times 10^{5}\right)$ were transfected with miR-98 mimics or pcDNA3.1 vector containing ITGB3 by Lipofectamine 2000 (Thermo Fisher Scientific) according to the manufacturer's instructions. Briefly, PC9, SKMES-1, and A549 cells were seeded in six-well plates and incubated for 24 hours to be $80 \%-90 \%$ confluent. The target PC9 and SKMES-1 cells were transfected with $50 \mathrm{nM}$ of miR-98 mimics or mimic control (controls).

\section{Luciferase reporter assay}

Fragments of the $3^{\prime}$-UTR of ITGB3 harboring the predicted miR-98-binding sites were cloned into the firefly luciferase reporter plasmid pMIR-Report (Ambion, Austin, TX, USA) according to the manufacturer's instructions. After 36-hour transfection for controls or miR-98 mimics group cells, cells were harvested and lysed, and luciferase reporter activities were measured using Dual-Glo ${ }^{\circledR}$ Luciferase Assay System (Promega Corporation).

\section{Nude mouse models}

A549 cells transfected with miR-98 mimics or controls were transplanted into nude mice (6-week old, weighing 25-30 g, $\mathrm{n}=6$ ), and tumor volume was measured every 5 days using a vernier caliper. Mice were kept in a temperature-controlled room with a 12 hour light/dark cycle, with free access to food and water. Mice were sacrificed on day 25, and xenografts were weighted. Moreover, the expression level of ITGB3 was detected by using western blotting analyses. All animal experimental protocol was approved by the Institutional Animal Care and Use Committee of the First Affiliated Hospital of Zhengzhou University.

\section{Statistical analysis}

The Statistical Package for Social Sciences software (Windows version release 17.0; SPSS Inc., Chicago, IL, USA) was applied for statistical analyses, including $t$-test and one-way ANOVA method of square-deviation.

\section{Results \\ miR-98 was downregulated in lung cancer cells and lung cancer tissues}

Table 1 shows a summary of patient characteristics and some pathological features. Median age was 62 years 
(range, 45-77) and 61.5\% were males. Fifteen (57.7\%) patients had smoking history. Eight (44.4\%) patients had stage I disease and 18 stage II. Twenty-two (84.6\%) patients had adenocarcinoma and four (15.4\%) large cell carcinoma. One metastatic site was found in eleven patients (42.3\%) and over two metastatic sites in seven patients (26.9\%). According to the quantitative real-time polymerase chain reaction result, the relative expression level of miR-98 in different lung cancer tissues and cells are shown in Figure 1A and B. Compared to normal tissues, miR-98 was significantly downregulated in lung cancer tissues, with a ratio of $0.27 \pm 0.08$ vs $1.0 \pm 0.02$. Besides, the expression of miR-98 was also downregulated in A549, SKMES-1, PC9, H1650, HCC827, and NCL-H358 lung cells, with the corresponding values of relative expression $0.24 \pm 0.08,0.31 \pm 0.07,0.45 \pm 0.08$, $0.52 \pm 0.12,0.53 \pm 0.11$, and $0.65 \pm 0.09$, respectively.

\section{Overexpression of miR-98 inhibits cell proliferation of lung cancer cells}

Compared with the control group, miR-98 was significantly upregulated in lung cancer cells transfected with miR-98 mimics, with a value of $4.37 \pm 0.39$ in PC9 cell and $3.56 \pm 0.34$ in A549 cell (Figure 1C). To study the possible effect of miR-98 on proliferation of lung cancer cells, MTT assays were applied. When compared with the control group, the relative absorbance was significantly lower in the miR-98 mimics group, both in PC9 and A549 cells (Figure 1D and E). The statement that miR-98 has an inhibitory effect on cell proliferation of lung cancer cells was also supported by the result of colony formation assay. As shown in Figure 1F, miR-98 significantly suppressed the ability of colony formation of PC9 and A549 cells compared to controls.

\section{Overexpression of miR-98 inhibits cell migration and invasion of lung cancer cells}

The effect of miR-98 on cell migration and invasion in PC9 and A549 lung cancer cells was studied by transwell assays. As shown in Figure 2A and B, compared with the control group, the number of migrated cells was only $39.6 \pm 7.5$ and $30.3 \pm 5.8$ in PC 9 and A549 cells, respectively, in the miR-98 mimics group, whereas the corresponding cell number was $109.8 \pm 10.3$ and $87.6 \pm 13.9$, respectively, in the control group. The number of invaded cells was $16.9 \pm 2.1$ and $25.8 \pm 2.5$ in PC9 and A549 cells transfected with miR-98 mimics, compared to the cells transfected with controls, with the invaded cell number of $36.3 \pm 4.7$ and $52.6 \pm 6.3$, respectively (Figure 2C and D).

\section{miR-98 negatively regulates ITGB3 expression via binding to the $3^{\prime}-$ UTR of ITGB3 mRNA}

To investigate the possible regulating role of miR-98 on ITGB3 expression, miR-98 target luciferase reporter assay aiming to the fragments of the $3^{\prime}$-UTR of ITGB3 was applied (Figure 3A). The results showed that in the wild-type background, the luciferase reporter activity was reduced to approximately one-third in the miR-98 mimics group compared to the controls group, while there were no obvious differences between these two groups with the mutation of 3'-UTR of ITGB3 (Figure 3B). These data suggested that miR-98 regulated ITGB3 expression via binding miR-98 to 3'-UTR of ITGB3 mRNA. Then, the relative expression level of ITGB3 was compared between to confirm the regulatory role of miR-98 on ITGB3 expression. As shown in Figure 3C, the relative expression level of ITGB3 was downregulated in the miR-98 mimics group compared to that in the control group in PC9 and SKMES-1 lung cancer cells. Moreover, to confirm that miR-98 suppresses proliferation of A549 cells by regulating the expression of ITGB3, we observed the effects of miR-98 on the relative absorbance of A549 in MTT assay. As shown in Figure 3D and E, miR-98 significantly downregulated the level of ITGB3 and reduced the relative absorbance of A549. Nevertheless, upregulation of ITGB3 resisted the inhibitory effect of miR-98 on proliferation of A549.

\section{miR-98 reduces the volume and weight of tumor in vivo}

The effect of miR-98 on lung tumor was verified in nude mice models. As shown in Figure 4A, compared with those in the control group, the tumors notably shrank in the miR-98 mimics group after 10 days, 15 days, 20 days, and 25 days. The final tumor weight was also reduced in the miR-98 mimics group (Figure 4B), and ITGB3 was a downregulated expression in the xenografts of miR-98 mimics group compared to that in the control group (Figure 4C).

\section{Discussion}

In this study, we found that miR-98 inhibited proliferation, migration, and invasion in lung cancer cells. As shown in previous studies, many genetic factors were involved in the occurrence and development of lung cancer, and among them, miRs are a diverse set of factors that cannot be ignored. ${ }^{10,32-34}$ For example, miR-30b/c inhibits NSCLC cell proliferation by targeting Rab $18,{ }^{21} \mathrm{miR}$ let-7c inhibits migration and invasion of human NSCLC by targeting ITGB3 and MAP4K3;31 

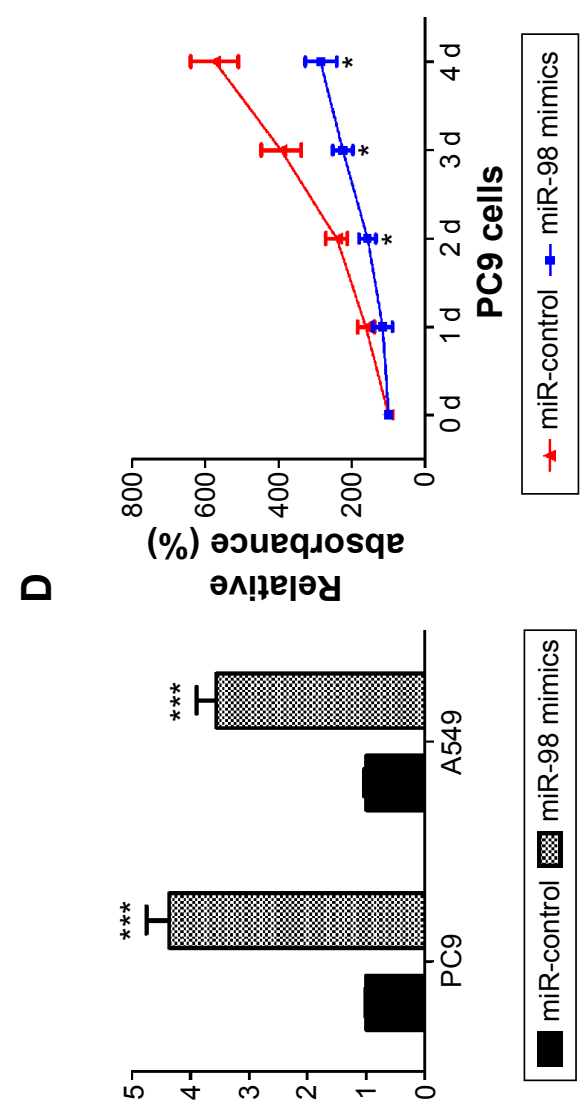

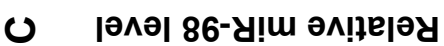

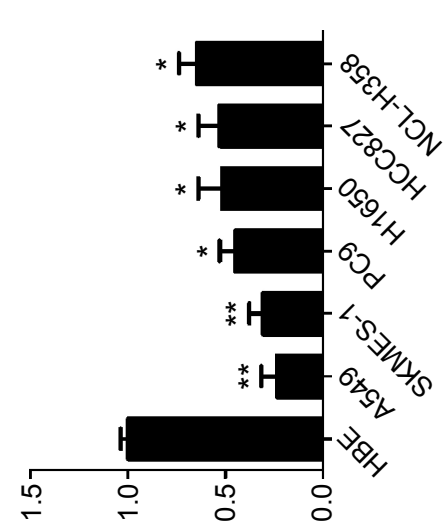

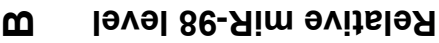

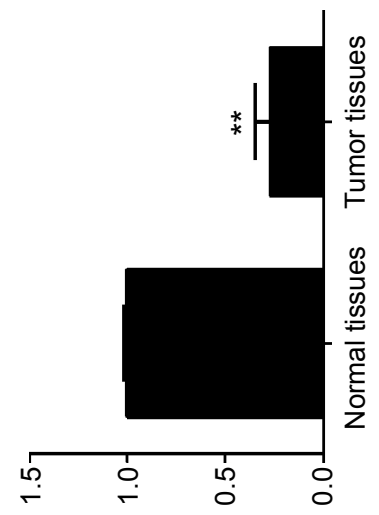

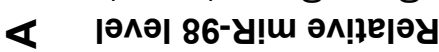

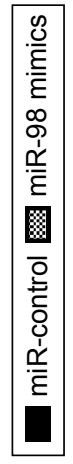

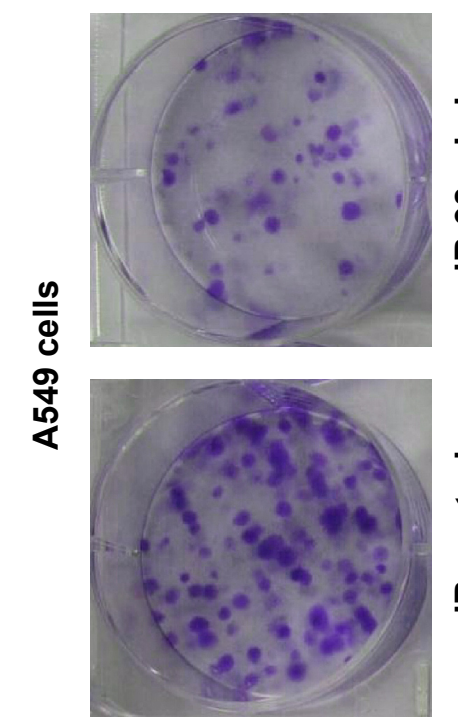

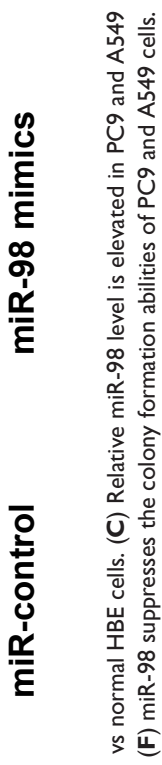
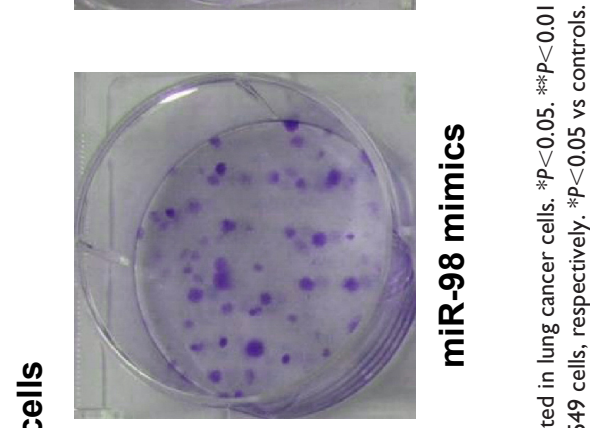

ర్

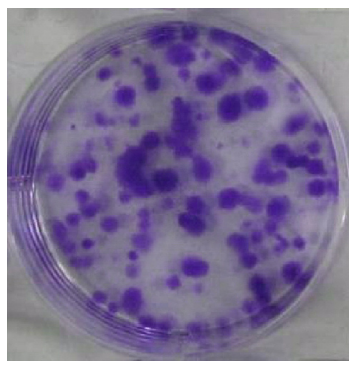

山
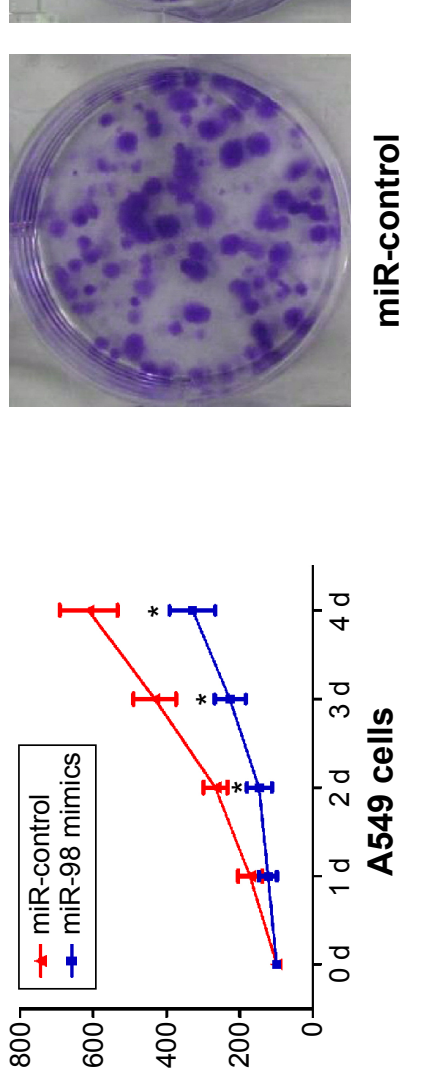

(\%) әэuequosqe

әм!ฺ리맘 
A

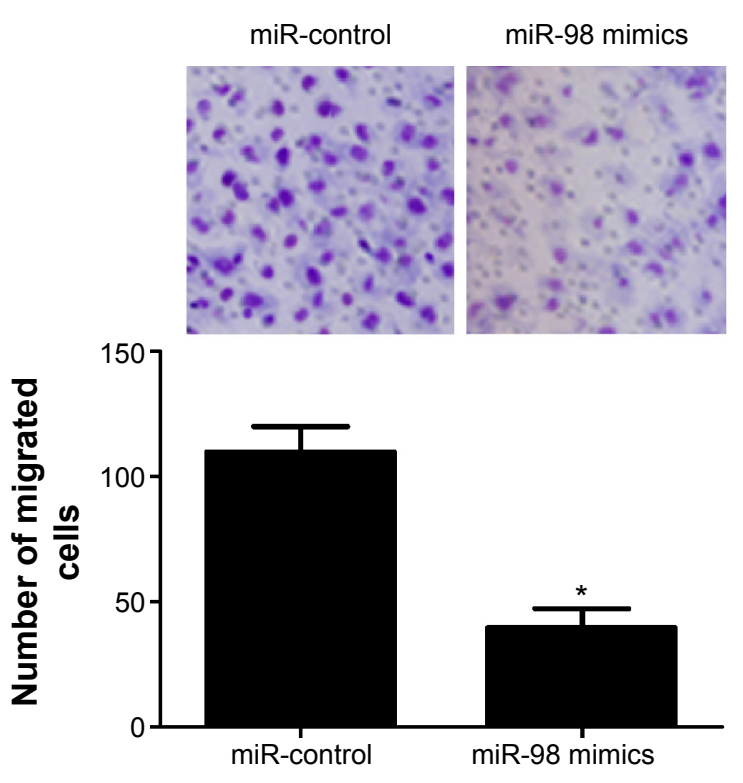

C

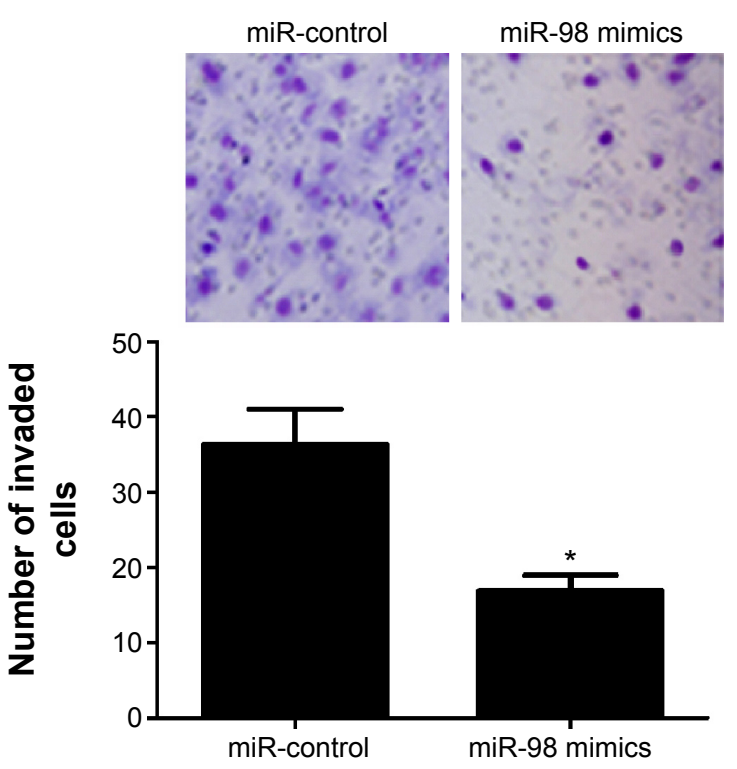

B

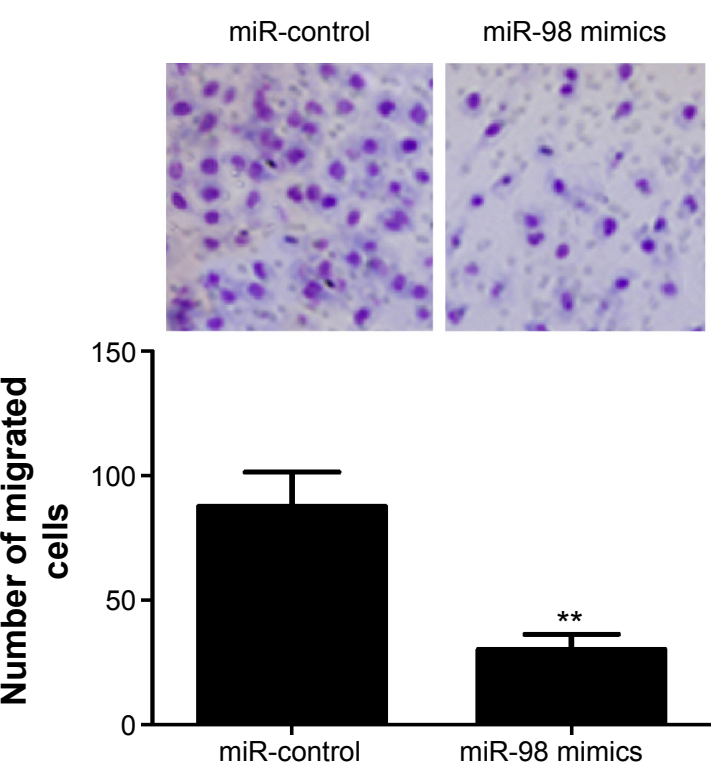

D A549 cells

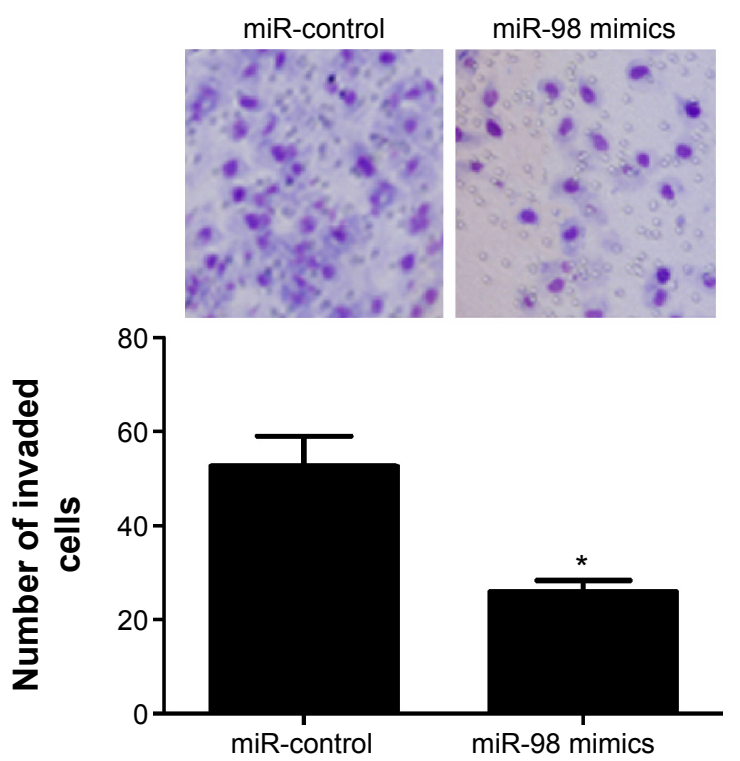

Figure 2 miR-98 inhibits migration and invasion of lung cancer cells.

Notes: (A and B) The number of migrated PC9 and A549 cells is decreased after transfection with miR-98 mimics. $* P<0.05$, $* * P<0.01$ vs controls. (C and D) Overexpression of miR-98 reduces the number of invaded $\mathrm{PC} 9$ and $\mathrm{A} 549$ cells. $* \mathrm{P}<0.05$ vs controls.

miR-99a promotes proliferation, migration, and invasion in NSCLC A549 and H1299 cells; ${ }^{35}$ and so on.

However, the role of miR-98 in lung cancer pathogenesis is still poorly understood. As reported by previous studies, miR-98 was supposed to work as a therapeutic target inhibiting prostate cancer growth and as a biomarker induced by vitamin $\mathrm{D},{ }^{26}$ miR-98 inhibited migration and invasion of human esophageal squamous cell carcinoma via regulating enhancer of zeste homologue $2,{ }^{24}$ enhancer of zeste homologue 2 -specific miR-98 inhibited human ovarian cancer stem cell proliferation via regulating the $\mathrm{pRb}-\mathrm{E} 2 \mathrm{~F}$ pathway, ${ }^{25}$ and miR-98 may not directly, but through the intermediate factor, played a role in the pathogenesis of human cancer. Many possible intermediate factors were considered in this study. Among these intermediate factors, the integrins, which reported to play important roles in signal transduction, especially in the pathogenesis of human cancer, ${ }^{26}$ were specially investigated. The ITGB3, a key player in tumor growth and metastasis, was reported to involve in pathogenesis of many cancers, eg, ITGB3 was reported to work as a key regulator in reactive oxygen species-induced migration 


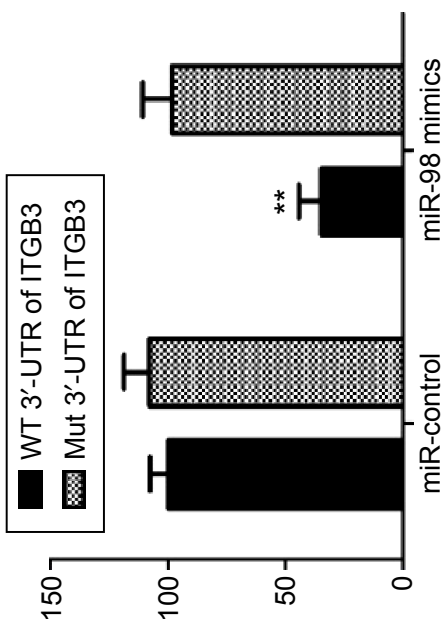

(\%) К!

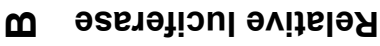
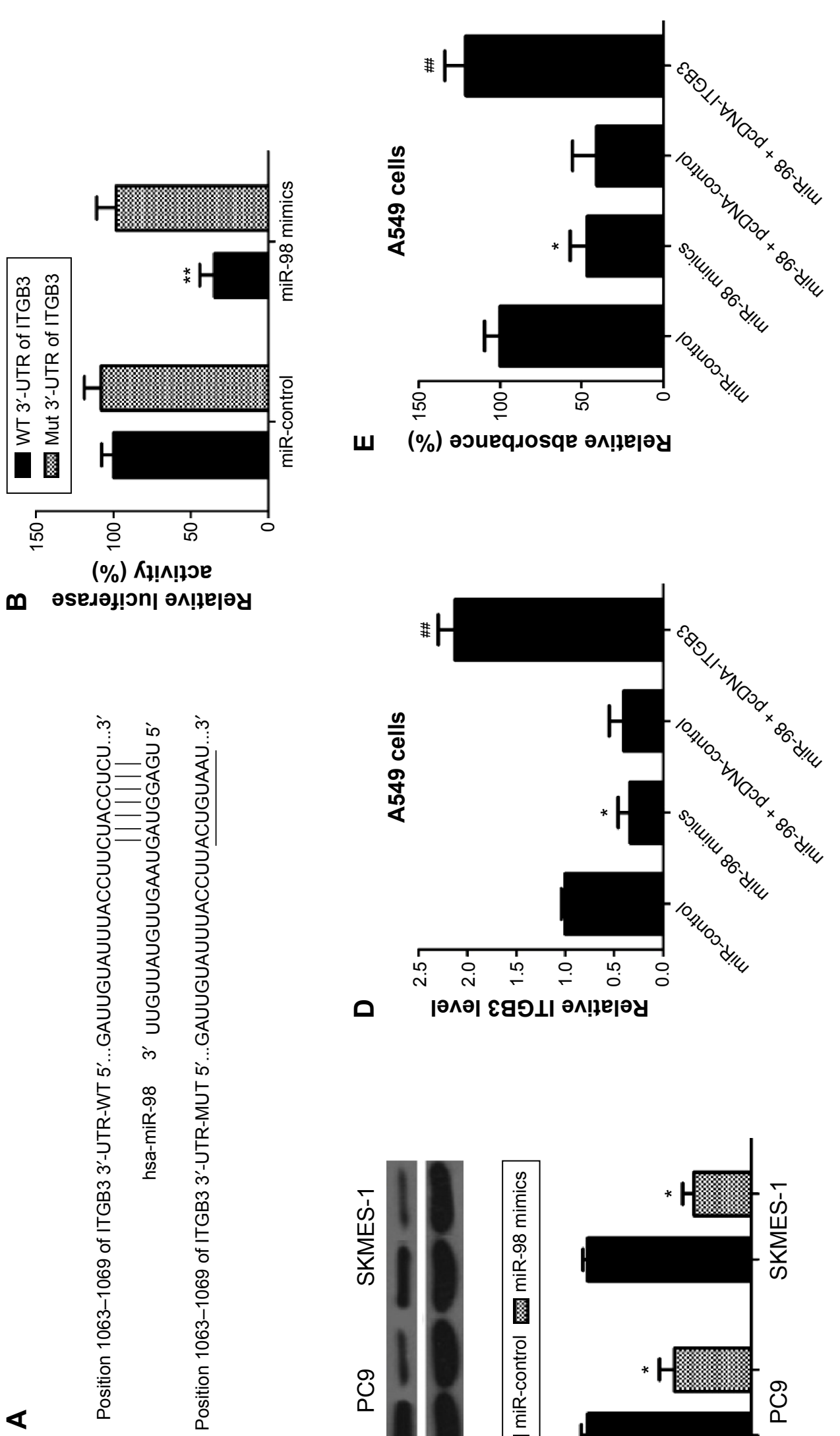

ш
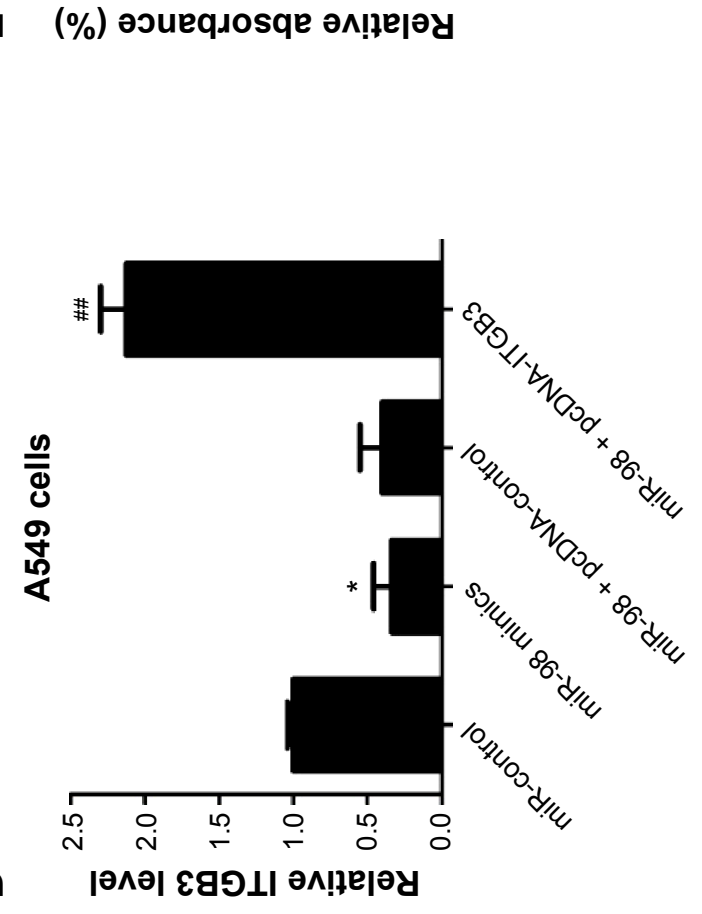

ర্

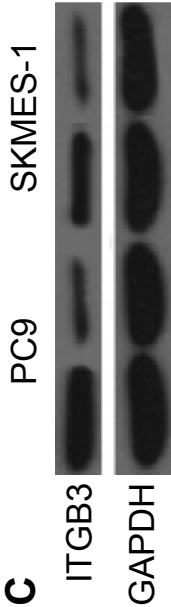

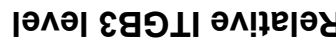

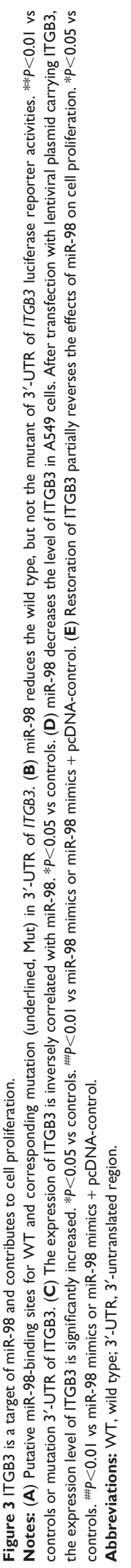


A

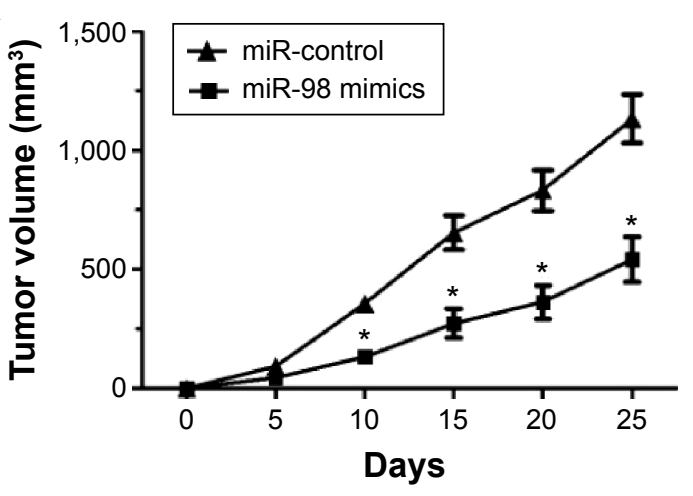

B

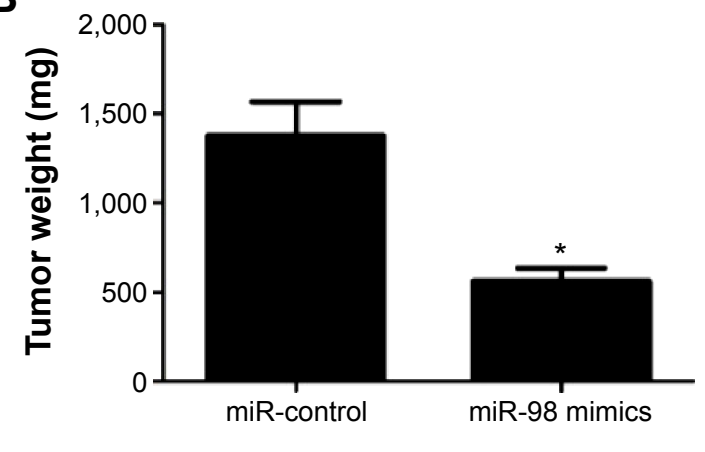

C

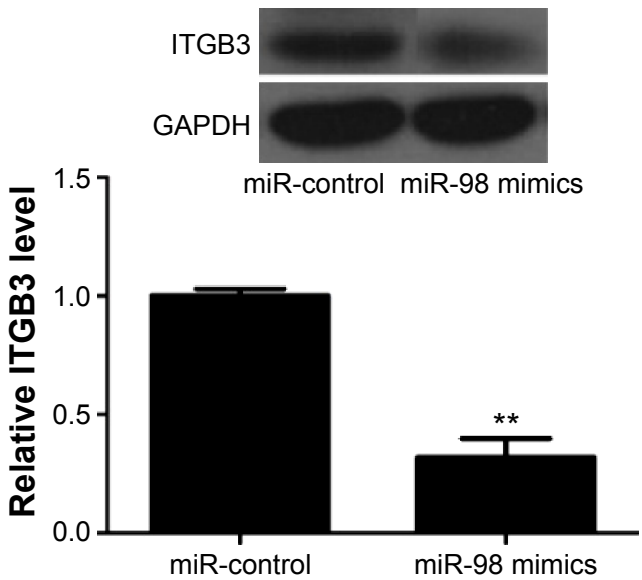

Figure 4 miR-98 suppresses tumor formation in vivo.

Notes: (A) miR-98 overexpressing cells or control A549 cells were injected subcutaneously into nude mice ( $\mathrm{n}=6$ ). The tumor volumes were measured every 5 days, and the mice were sacrificed on day 25 . miR-98 decreases the tumor volumes. $* P<0.05$ vs controls. (B) miR-98 reduces tumor weights. (C) The level of ITGB3 is decreased in miR-98 overexpressing A549 cells. $* * P<0.01$ vs controls.

and invasion of colorectal cancer cells, ${ }^{27,28} \mathrm{miR}$ let- $7 \mathrm{c}$ inhibited migration and invasion of human NSCLC through targeting ITGB $3,{ }^{31}$ and so on.

To investigate the possible role regulation of miR-98 via the ITGB3 on lung cancer, a series of research experiments were designed in this study. We found that miR-98 was a downregulated expression in lung cancer cells and lung cancer tissues, and further research indicated that overexpression of miR-98 can inhibit cell proliferation, migration, and invasion of lung cancer cells. Then possible regulating role of miR-98 on ITGB3 expression was investigated, by luciferase reporter assay, western blotting, and MTT assay. We found that miR-98 negatively regulated ITGB3 expression via binding to the 3'-UTR of ITGB3 mRNA. When mutated the putative binding site, the inhibitory effect was almost completely relieved, and overexpression of ITGB3 reduced the inhibition effect on cell proliferation by miR-98 in lung cancer cells. Finally, all these regulatory effects were verified by the results of nude mice models that miR-98 reduced the volume and weight of tumor in vivo, and this effect may be via inhibiting the expression of ITGB3 in lung cancer cells.
We found that miR-98 inhibited cell proliferation, migration, and invasion in lung cancer cells, and miR-98 also negatively regulated ITGB3 expression via binding miR-98 to the 3 -UTR of ITGB3 mRNA in this study. It was also reported that miR let-7c inhibited migration and invasion of human NSCLC through targeting ITGB3. ${ }^{27}$ We speculated a possible underlying mechanism of miR-98 on inhibiting lung cancer pathogenesis via targeting ITGB3 as follows. Via directly binding to the 3'-UTR of ITGB3 mRNA, miR-98 inhibited the expression of ITGB3 on posttranscriptional level via directly binding to its regulatory 3 '-UTR. This leads to a downregulated expression of ITGB3 and consequently reduced cell proliferation, migration, and invasion in lung cancer cells. Finally, this is associated with a reduction in the volume and weight of tumor tissues and ultimately inhibited the occurrence and development of lung cancer. These results may provide a framework for further analyzing the possible underlying mechanisms of miR-98 on inhibiting lung cancer pathogenesis. However, larger prospective studies about evaluating the association of miR-98 with ITGB3 expression and the pathogenesis of human lung cancer are also needed 
to confirm these findings in larger different populations and to elucidate the underlying molecular mechanisms.

\section{Disclosure}

The authors report no conflicts of interest in this work.

\section{References}

1. McErlean A, Ginsberg MS. Epidemiology of lung cancer. Semin Roentgenol. 2011;46(3):173-177.

2. Siegel R, Ma JM, Zou ZH, Jemal A. Cancer statistics, 2014. CA Cancer J Clin. 2014;64(1):9-29.

3. Zhou C. Lung cancer molecular epidemiology in China: recent trends. Transl Lung Cancer Res. 2014;3(5):270-279.

4. Ferlay J, Soerjomataram I, Dikshit R, et al. Cancer incidence and mortality worldwide: sources, methods and major patterns in GLOBOCAN 2012. Int J Cancer. 2015;136(5):E359-E386.

5. Chen WQ, Zheng RS, Zeng HM, Zhang SW. Epidemiology of lung cancer in China. Thoracic Cancer. 2015;6(2):209-215.

6. Pinsky PF, Church TR, Izmirlian G, Kramer BS. The national lung screening trial: results stratified by demographics, smoking history, and lung cancer histology. Cancer. 2013;119(22):3976-3983.

7. Fajersztajn L, Veras M, Barrozo LV, Saldiva P. Air pollution: a potentially modifiable risk factor for lung cancer. Nat Rev Cancer. 2013;13(9): 674-678.

8. Li TY, Zhang F. Screening of lung cancer related SNPs and CNVs with SNP microarrays. Eur Rev Med Pharmacol Sci. 2015;19(2):225-234.

9. Zhang J, Zhou JB, Lin XF, Wang Q, Bai CX, Hong QY. Prevalence of undiagnosed and undertreated chronic obstructive pulmonary disease in lung cancer population. Respirology. 2013;18(2):297-302.

10. Jeong HC. Clinical aspect of microRNA in lung cancer. Tuberc Respir Dis (Seoul). 2014;77(2):60-64.

11. Kang HW, Crawford M, Fabbri M, et al. A mathematical model for microRNA in lung cancer. PLoS One. 2013;8(1):e53663.

12. Oh SY, Brandal S, Kapur R, Zhu Z, Takemoto CM. Global microRNA expression is essential for murine mast cell development in vivo. Exp Hematol. 2014;42(10):919.e-923.e.

13. Liang J, Liu X, Xue H, Qiu B, Wei B, Sun K. MicroRNA-103a inhibits gastric cancer cell proliferation, migration and invasion by targeting c-Myb. Cell Prolif. 2015;48(1):78-85.

14. Saki N, Abroun S, Soleimani M, et al. Involvement of microRNA in T-Cell differentiation and malignancy. Int J Hematol Oncol Stem Cell Res. 2015;9(1):33-49.

15. Cui SQ, Wang H. MicroRNA-144 inhibits the proliferation, apoptosis, invasion, and migration of osteosarcoma cell line F5M2. Tumour Biol. Epub 2015 Apr 9.

16. Meerson A, Traurig M, Ossowski V, Fleming JM, Mullins M, Baier LJ. Human adipose microRNA-221 is upregulated in obesity and affects fat metabolism downstream of leptin and TNF-alpha. Diabetologia. 2013;56(9):1971-1979.

17. Leppert U, Eisenreich A. The role of tissue factor isoforms in cancer biology. Int J Cancer. 2015;137(3):497-503.

18. Eisenreich A, Zakrzewicz A, Huber K, et al. Regulation of pro-angiogenic tissue factor expression in hypoxia-induced human lung cancer cells. Oncol Rep. 2013;30(1):462-470.

OncoTargets and Therapy

\section{Publish your work in this journal}

OncoTargets and Therapy is an international, peer-reviewed, open access journal focusing on the pathological basis of all cancers, potential targets for therapy and treatment protocols employed to improve the management of cancer patients. The journal also focuses on the impact of management programs and new therapeutic agents and protocols on

Submit your manuscript here: http://www.dovepress.com/oncotargets-and-therapy-journal
19. Rusek AM, Abba M, Eljaszewicz A, Moniuszko M, Niklinski J, Allgayer H. MicroRNA modulators of epigenetic regulation, the tumor microenvironment and the immune system in lung cancer. Mol Cancer. 2015;14(1):34.

20. Skrzypski M, Czapiewski P, Goryca K, et al. Prognostic value of microRNA expression in operable non-small cell lung cancer patients. Br J Cancer. 2014;110(4):991-1000.

21. Zhong K, Chen K, Han L, Li B. MicroRNA-30b/c inhibits non-small cell lung cancer cell proliferation by targeting Rab18. BMC Cancer. 2014; $14: 703$.

22. Shi Y, Liu C, Liu X, Tang DG, Wang J. The microRNA miR-34a inhibits non-small cell lung cancer (NSCLC) growth and the CD44hi stem-like NSCLC cells. PLoS One. 2014;9(3):e90022.

23. Guo J, Feng Z, Huang Z, Wang H, Lu W. MicroRNA-217 functions as a tumour suppressor gene and correlates with cell resistance to cisplatin in lung cancer. Mol Cells. 2014;37(9):664-671.

24. Huang SD, Yuan Y, Zhuang CW, et al. MicroRNA-98 and microRNA214 post-transcriptionally regulate enhancer of zeste homolog 2 and inhibit migration and invasion in human esophageal squamous cell carcinoma. Mol Cancer. 2012;11:51.

25. Liu T, Hou L, Huang Y. EZH2-specific microRNA-98 inhibits human ovarian cancer stem cell proliferation via regulating the $\mathrm{pRb}-\mathrm{E} 2 \mathrm{~F}$ pathway. Tumour Biol. 2014;35(7):7239-7247.

26. Ting HJ, Messing J, Yasmin-Karim S, Lee YF. Identification of microRNA-98 as a therapeutic target inhibiting prostate cancer growth and a biomarker induced by vitamin D. J Biol Chem. 2013;288(1):1-9.

27. Lei Y, Huang K, Gao C, et al. Proteomics identification of ITGB3 as a key regulator in reactive oxygen species-induced migration and invasion of colorectal cancer cells. Mol Cell Proteomics. 2011; 10(10):M110.005397.

28. Ye P, Li Z, Jiang H, Liu T. SNPs in microRNA-binding sites in the ITGB1 and ITGB3 3'-UTR increase colorectal cancer risk. Cell Biochem Biophys. 2014;70(1):601-607.

29. Löbel M, Bauer S, Meisel C, et al. CCN1: a novel inflammationregulated biphasic immune cell migration modulator. Cell Mol Life Sci. 2012;69(18):3101-3113.

30. Gauck S, Schultheiss HP, Rauch U, Eisenreich A. Modulation of the isoform expression of Cyr61 and integrin- $\alpha \mathrm{V}$ in human microvascular endothelial cells. Cardio Vasc Syst. 2013;1:8.

31. Zhao B, Han H, Chen J, et al. MicroRNA let-7c inhibits migration and invasion of human non-small cell lung cancer by targeting ITGB3 and MAP4K3. Cancer Lett. 2014;342(1):43-51.

32. Huang J, Wu J, Li Y, et al. Deregulation of serum microRNA expression is associated with cigarette smoking and lung cancer. Biomed Res Int. 2014;2014:364316.

33. Lønvik K, Sørbye SW, Nilsen MN, Paulssen RH. Prognostic value of the MicroRNA regulators dicer and drosha in non-small-cell lung cancer: co-expression of drosha and miR-126 predicts poor survival. BMC Clin Pathol. 2014;14(1):45.

34. Zhang F, Li Y, Zhou Q. Advances in the relationship between microRNA and cisplatin resistance of lung cancer. Zhongguo Fei Ai Za Zhi. 2014;17(3):269-272.

35. Chen C, Zhao Z, Liu Y, Mu D. microRNA-99a is downregulated and promotes proliferation, migration and invasion in non-small cell lung cancer A549 and H1299 cells. Oncol Lett. 2015;9(3):1128-1134.

\section{Dovepress}

patient perspectives such as quality of life, adherence and satisfaction. The manuscript management system is completely online and includes a very quick and fair peer-review system, which is all easy to use. Visit http://www.dovepress.com/testimonials.php to read real quotes from published authors. 